\title{
Neurofuzzy Model of Formation of Knowledge Bases for Selection of Geological and Technical Measures in Oil Fields
}

\author{
Oleg Yuryevich Panischev ${ }^{1}$, Ekaterina Nikolaevna Ahmedshina ${ }^{2}$, Dina Vladimirovna Kataseva ${ }^{3}$, Igor Vyacheslavovich Anikin ${ }^{4}$, \\ Alexey Sergeevich Katasev ${ }^{5}$, Amir Muratovich Akhmetvaleev ${ }^{6}$, Arslan Valerievich Nasybullin ${ }^{7}$ \\ ${ }^{1}$ Researcher of the Research Laboratory of Near Space Research of the Kazan (Volga) Federal University; \\ Scopus ID: 8355604900; ORCID: 0000-0001-5490-912X, Kazan Federal University, \\ ${ }^{2}$ Candidate of Physical and Mathematical Sciences, Senior Researcher of the Research Laboratory for Near Space Research of \\ the Kazan (Volga) Federal University; Russia. Scopus ID: 55488733700; ORCID: 0000-0002-8681-8131, Kazan Federal \\ University, Russia. \\ ${ }^{3}$ Senior Lecturer of the Department of Information Security Systems of the Institute of Computer Technologies and Information \\ Protection of the Kazan National Research Technical University named after A.N. Tupolev-KAI; Russia. \\ e-mail: DVKataseva@kai.ru; Scopus ID: 57193401954; ORCID: 0000-0001-6141-8329, Kazan National Research Technical
}

University named after A.N. Tupolev,

${ }^{4}$ Doctor of Technical Sciences, Professor, Head of the Department of Information Security Systems of the Institute of Computer Technologies and Information Security of the Kazan National Research Technical University named after A.N. Tupolev-KAI; Russia. Scopus ID: 56538191100; ORCID: 0000-0001-9478-4894, Kazan National Research Technical University named after

\section{A.N. Tupolev,}

${ }^{5}$ Doctor of Technical Sciences, Professor of the Department of Information Security Systems of the Institute of Computer Technologies and Information Security of the Kazan National Research Technical University named after A.N. Tupolev TupolevKAI; Russia. Scopus ID: 57193408902; ORCID: 0000-0002-9446-0491, Kazan National Research Technical University named

$$
\text { after A.N. Tupolev, }
$$

${ }^{6}$ Candidate of Technical Sciences, Associate Professor of the Department of Information Security Systems of the Institute of Computer Technologies and Information Security of the Kazan National Research Technical University named after A.N. Tupolev-KAI; Russia. Scopus ID: 57202913457; ORCID: 0000-0003-0384-9539, Kazan National Research Technical University named after A.N. Tupolev,

${ }^{7}$ Nasybullin Arslan Valerievich, Doctor of Technical Sciences, Professor, Head of the Department of Development and Operation of Oil and Gas Fields of the Almetyevsk State Oil Institute; Russia.

Scopus ID: 24765148900; ORCID: 0000-0003-1943-5082, Almetyevsk State Oil Institute,

\begin{abstract}
This paper poses and solves the problem of developing the upto-date neuro-fuzzy model of formation of a knowledge base for an intelligent decision-making support system for selection of geological and technical measures in oil fields. The analysis of the traditional approach to the formation of fuzzy knowledge bases made it possible to reveal its shortcomings associated with the need to attract experts, structure and formalize the system of decision-making rules by them. This process is laborious and does not always provide an acceptable result. To eliminate the disadvantages of the traditional approach, we proposed an approach to the automatic formation of a knowledge base based on the construction of a neuro-fuzzy model of a collective of fuzzy neural networks. We formulated the requirements in view of the formed fuzzy rules. We developed a scheme for using the rules of the knowledge base to solve the problem of selecting geological and technical measures in oil fields. We tested the generated knowledge base on the example of solving the problem of selecting geological and technical measures for various wells of the Feofanovskoye Field. Application of the knowledge base made it possible to select a list of optimal
\end{abstract}

measures for given wells. The experiment results are satisfactory and are confirmed by the positive expert assessments, selecting geological and technical measures at this field.

Keywords- Neuro-Fuzzy Model, Knowledge Base, Geological And Technical Measures, Oil Field, DecisionMaking Support

\section{INTRODUCTION}

Currently, artificial intelligence technologies are being actively introduced to solve practical problems in various subject areas of human activity [1-5]. One of these areas is the oil industry, for which it is important to solve a number of problems to increase the oil field development efficiency [6$8]$. The task of selecting geological and technical measures (GTM) to enhance oil recovery is urgent in this subject area [9].

The solution to this problem is accompanied by a number of difficulties. The main ones are possible fuzziness, uncertainty and incompleteness of knowledge about the studied field [10]. 
Under these conditions, it is very difficult to effectively use traditional methods of mathematical statistics, probabilistic approaches and hydrodynamic equations.

To solve the problem of selecting GTM in the oil fields, it is advisable to use intelligent decision-making support systems (DSS) [11-13] based on the fuzzy logic methods and fuzzy inference algorithms [14]. Such systems, due to the knowledge of experts accumulated in them, make it possible to recommend a decision-maker (DM), rational in the current conditions of GTM [15]. At the same time, the proposed solution is interpretable and understandable for a person, which increases its reliability and confidence level among the DM. The knowledge base used in this case can be formed by an expert method $[16,17]$, or the process of its formation can be automated [18, 19]. In the latter case, it is currently relevant to use Data Mining methods to form fuzzy knowledge bases [20-22]. As the data analysis tool, it is relevant to use a neuro-fuzzy model formed as a result of training a fuzzy neural network (FNN) [23]. At the same time, the model, having been trained on the initial data characterizing the oil field and specific production wells, will make it possible to form a fuzzy knowledge base for the GTM selection.

\section{METHODS}

In any decision-making support system, its main component is the knowledge base [24]. At the same time, an approach with the involvement of experts is implemented to form a knowledge base in most of the existing expert systems in various subject areas, in particular in the oil industry $[10,16]$.
For example, the work [7] proposes the methods for solving the problem of developing recommendations on the GTM appointment. The practical use of the approach made it possible to form a knowledge base that includes many rules of the following type:

IF the horizon type is "Devon" AND the period Rzab $<$ Rnas is more than 0.5 years AND the water cut is CLOSE ([0.70]\%) AND the productivity percentage drop is ABOUT ([17.100]\%) AND the reservoir pressure is ABOUT ([12.60] $\mathrm{MPa})$ AND the oil production rate is ABOUT ([2,max ${ }_{\text {Oil }}$ production rate] t/day) AND the type of well is "Extractive" AND the reservoir injectivity is MEDIUM or GREAT, THEN it is possible to use the DISIN $+\mathrm{HCl}$ technology at the well.

Such rules are formulated by experts and put into the knowledge base of expert systems for their use in the fuzzy inference mechanisms in the process of solving practical problems [25].

The main disadvantages of the expert approach to the formation of a knowledge base in the decision-making support systems are:

1) high labor intensity (an expert needs to formulate, structure and formalize a set of rules);

2) low efficiency of practical use of the expert knowledge bases.

To eliminate them, this work implements an approach to the automatic formation of the knowledge base without an involvement of experts. Figure 1 shows a diagram of the proposed approach.

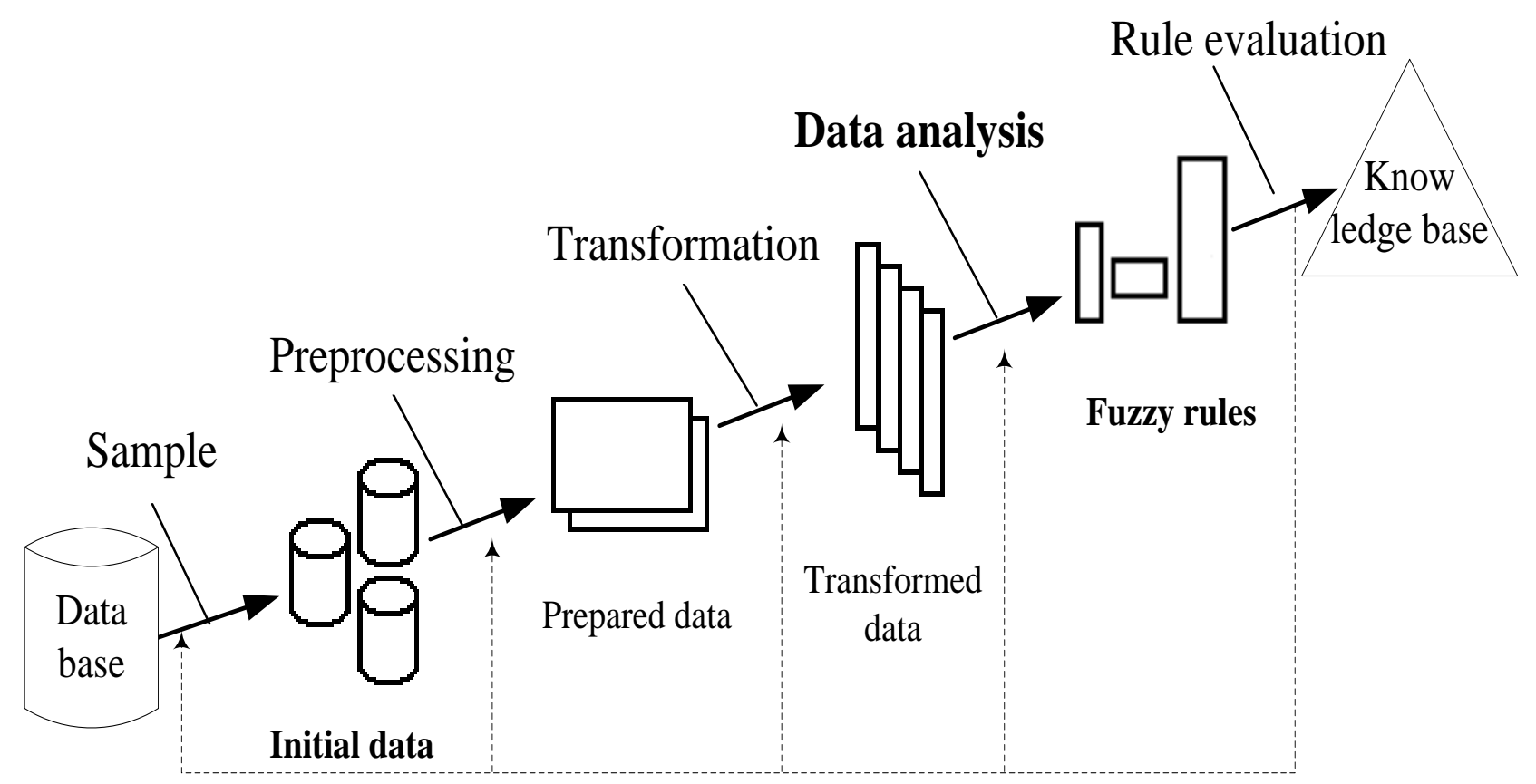

Fig 1. Data analysis and knowledge base formation scheme 
As can be seen from the figure, the GTM selection in the oil fields requires the use of fuzzy production rules of the corresponding type. The paper proposes to use the following type of rules [18]:

IF $x_{1}=\vec{A}_{1}\left(w_{1}\right)$ AND $x_{2}=\vec{A}_{2}\left(w_{2}\right)$ AND $\ldots x_{n}=\vec{A}_{n}\left(w_{n}\right)$, THEN $y=B[C F]$,

where $x_{i}$ - input variables, $w_{i} \in[0,1]$ - input weights, $\mu_{\tilde{A}_{i}}\left(x_{i}\right)$ - membership function, $y$ - output variable, $B-$ output value, $C F \in[0,1]$ - rule validity.

To create the rules of the form (1), it is proposed to use a specially developed neuro-fuzzy model. To build it, one need training and test data samples. At the same time, even the random nature of the samples does not guarantee high efficiency in the practical use of the knowledge base being formed. This approach is possible in case of data sampling, where the representativeness is beyond doubt. It is not always possible to obtain such initial data in real problems of neurofuzzy modeling and, in particular, in the oil industry. Therefore, it is advisable to train a fuzzy neural network iteratively several times, which is implemented in this study. For this purpose, we used the bootstrap method, which allows generating random data samples based on the method of random sampling with replacement [26].

As a result of applying this method, we built a set of fuzzy neural networks, which can be considered as a special neurofuzzy model of a parallel architecture (see Figure 2).

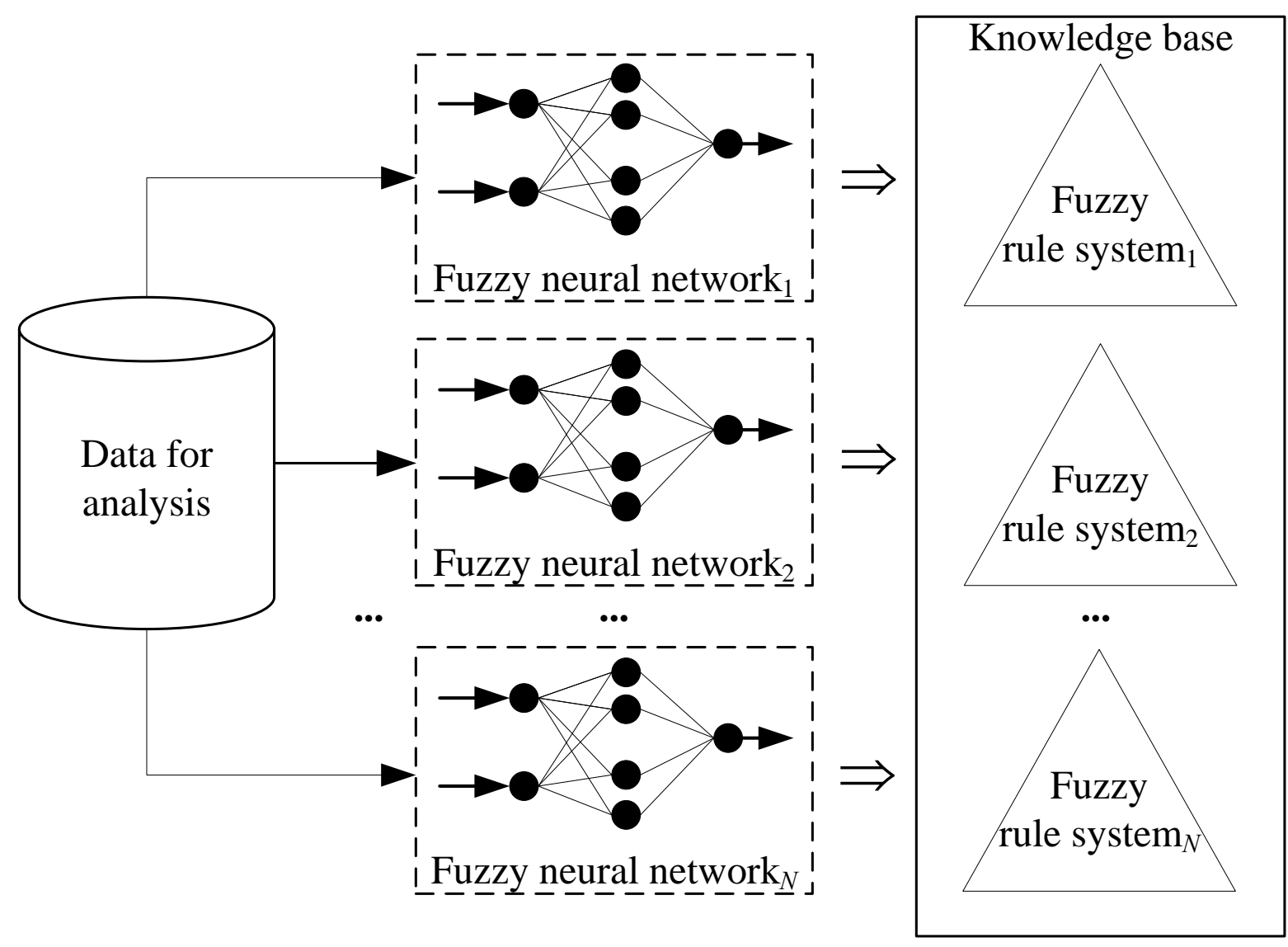

Figure 2. Scheme of forming a knowledge base based on a neuro-fuzzy model

In this scheme, training and testing of the corresponding fuzzy neural networks is performed on various random data samples.

To practically solve the GTM selection problem, it is necessary to set a problem and develop a scheme for the joint application of the knowledge base rules. In accordance with the task to be solved, the result of the GTM selection shall be considered the combination of intermediate results independently produced by each system of rules (see Figure 3). 


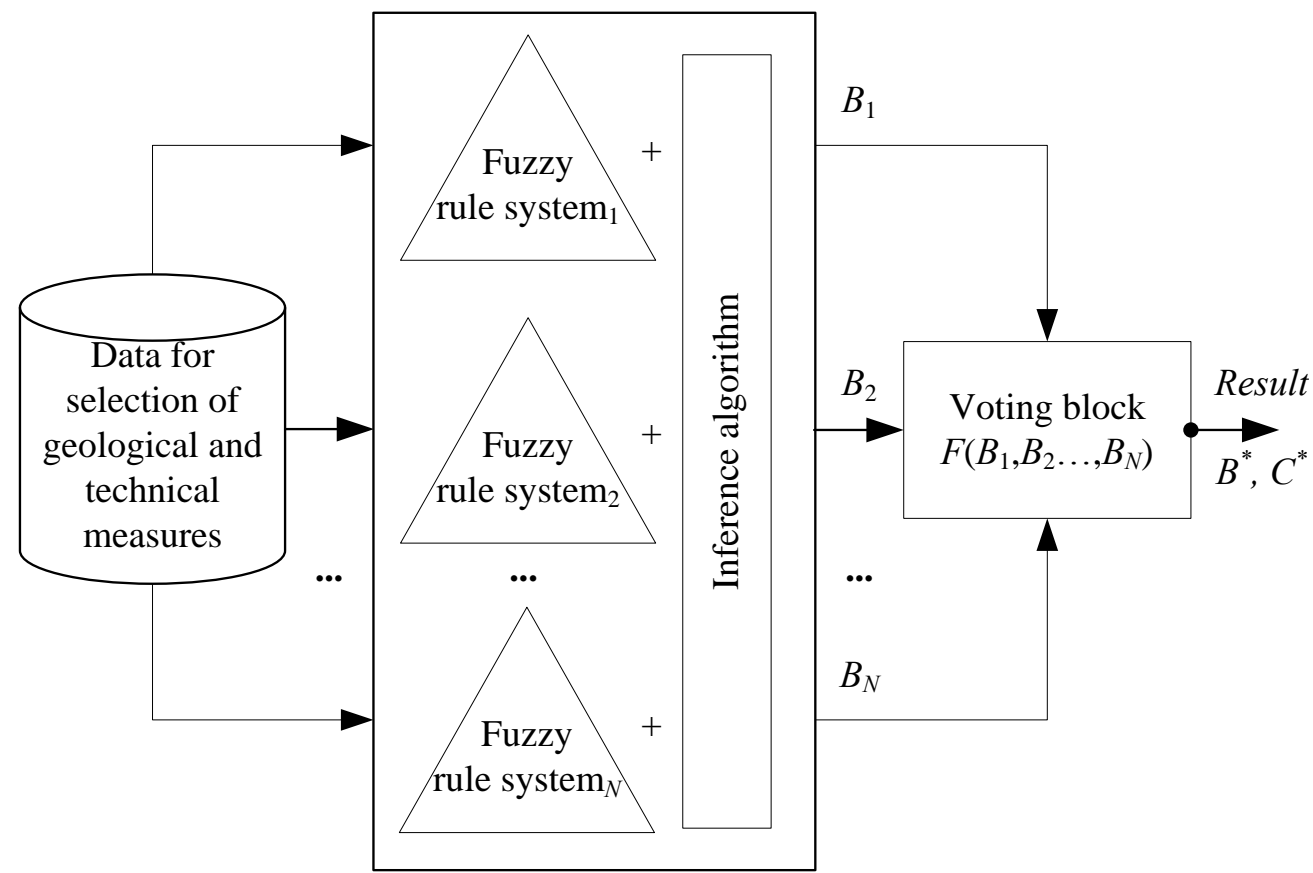

Figure 3. Scheme of joint use of knowledge base rules

The figure uses the following designations [27]: $F\left(B_{1}, B_{2}, \ldots\right.$, $B_{N}$ ) - voting rule, $B^{*} \in\left\{B_{1}, B_{2}, \ldots, B_{N}\right\}$ - required GTM, $C^{*}-$ comprehensive assessment of the decision reliability. The result of the final assessment is a specific GTM $B^{*}$, as well as a comprehensive assessment of its reliability $C^{*}$.

The solution to this problem made it possible to build a neurofuzzy model and form a knowledge base for the GTM selection in oil fields.

\section{RESULTS AND DISCUSSION}

We tested the formed knowledge base on the example of solving the problem of GRM selection for various wells of the Feofanovskoye Field (Lukoil OJSC). The following input parameters were used in the initial data with a volume of 15,000 records, characterizing the specified field over the past 5 years:

- rock group;

- absolute rock permeability;

- rock porosity;

- initial oil saturation;

- initial oil-saturated thickness;

- sweep efficiency;

- current oil reserves;

- minimum flow rate of adjacent wells;
- average flow rate of adjacent wells;

- maximum flow rate of adjacent wells;

- minimum water cut of adjacent wells;

- average water cut of adjacent wells;

- maximum water cut of adjacent wells.

The following GTM were used as the output parameter values, which were recommended by experts for assignment in the oil fields in the past:

- oil bitumen product;

- high molecular weight compounds;

- injection;

- water-swelling polymer;

- cavern creation;

- deep hydrochloric acid effect;

- silicate-gel system;

- nepheline;

- modified silicate-gel system;

- organic silicon compound;

- colloidal-selective mixture.

The use of the generated knowledge base made it possible to select a list of GTM for wells, based on the conditions of their current operation (see Table 1). 
International Journal of Engineering Research and Technology. ISSN 0974-3154, Volume 13, Number 11 (2020), pp. 3589-3595

(C) International Research Publication House. https://dx.doi.org/10.37624/IJERT/13.11.2020.3589-3595

Table 1. An Example of Geological and Technical Measures Recommended for Use in Production Wells

\begin{tabular}{|c|c|c|}
\hline Geological and technical measures & $\begin{array}{l}\text { The purpose of the geological } \\
\text { and technical measures }\end{array}$ & Validity assessment, $\%$ \\
\hline \multicolumn{3}{|c|}{ For well 687} \\
\hline Oil bitumen product & Water limitation & 82,6 \\
\hline High molecular weight compounds & Water limitation & 82,6 \\
\hline Injection & Water limitation & 78,9 \\
\hline Water-swellable polymer & Water limitation & 78,9 \\
\hline \multicolumn{3}{|c|}{ For well 312} \\
\hline Cavern creation & Stimulation & 100 \\
\hline Deep hydrochloric acid effect & Stimulation & 100 \\
\hline \multicolumn{3}{|c|}{ For well 314} \\
\hline Cavern creation & Stimulation & 100 \\
\hline Deep hydrochloric acid effect & Stimulation & 100 \\
\hline \multicolumn{3}{|c|}{ For well 414} \\
\hline Oil bitumen product & Water limitation & 60,79 \\
\hline High molecular weight compounds & Water limitation & 60,79 \\
\hline Injection & Water limitation & 52,6 \\
\hline Water-swellable polymer & Water limitation & 52,6 \\
\hline Silicate-gel system & Water limitation & 44,07 \\
\hline Nepheline & Water limitation & 44,07 \\
\hline Modified silicate-gel system & Water limitation & 44,07 \\
\hline Silicon-organic compound & Water limitation & 44,07 \\
\hline Colloid selective blend & Water limitation & 44,07 \\
\hline
\end{tabular}

The experiment results are satisfactory and are confirmed by the positive expert assessments, selecting geological and technical measures at this field.

\section{SUMMARY}

In this work, we substantiated the expediency of the formation and practical use of fuzzy knowledge bases of the production type for the GTM selection. We considered the features of solving this problem and forming a knowledge base as the main component of the system being developed. We analyzed the traditional approach to the formation of a fuzzy knowledge base. We proposed an approach based on the stages of the knowledge detection technology in databases. For the GTM selection, we proposed a special type of fuzzy rules and a neuro-fuzzy model for their formation. The generated knowledge base was tested on the example of solving the problem of selecting geological and technical measures for various wells of the Feofanovskoye Field (Lukoil OJSC). The use of the knowledge base made it possible to select the optimal list of measures for the given wells. The experiment results are satisfactory and are confirmed by the positive expert assessments, selecting geological and technical measures at this field.

\section{CONCLUSIONS}

Thus, the problem of development and use of a neuro-fuzzy model for the formation of knowledge bases for the GTM selection was solved in the work. The results of our studies have shown the effectiveness of the proposed approach to solving the problem. The formed knowledge base showed high adequacy, consistent with the expert assessments. This indicates its efficiency and the possibility of practical use for the GTM selection.

\section{ACKNOWLEDGEMENTS}

The work is performed according to the Russian Government Program of Competitive Growth of Kazan Federal University. This work was financially supported by the Ministry of Science and Higher Education of the Russian 
Federation in the framework of the Federal Target Program «Research and Development in Priority Directions for the Development of the Scientific and Technological Complex of Russia for 2014-2020» under the agreement on granting subsidies No. 05.604.21.0253 dated 12/02/19 on the topic «Creating technology for long-term investment planning for the effective development of oil fields based on highperformance computing and machine learning», a unique identifier is RFMEFI60419X0253.

\section{REFERENCES}

[1] Yuan Y. Research on the Reconstruction of Human Resource Management Based on Computer Big Data and Artificial Intelligence Technology. InJournal of Physics: Conference Series 2020 Jun 1 (Vol. 1574, No. 1, p. 012075). IOP Publishing.

[2] Huang Y. Research on Computer Network Security Analysis Modeling Based on Artificial Intelligence Technology. MS\&E. 2020 Jan;740(1):012114.

[3] Dagaeva M, Garaeva A, Anikin I, Makhmutova A, Minnikhanov R. Big spatio-temporal data mining for emergency management information systems. IET Intelligent Transport Systems. 2019 Sep 5;13(11):164957.

[4] Perfilieva IG, Yarushkina NG, Afanasieva TV, Romanov AA. Web-based system for enterprise performance analysis on the basis of time series data mining. InProceedings of the First International Scientific Conference "Intelligent Information Technologies for Industry”(IITI’16) 2016 (pp. 75-86). Springer, Cham.

[5] Rao W, Chen J. Risk Control System of Construction Engineering Based on Data Mining and Artificial Intelligence Technology. InData Processing Techniques and Applications for Cyber-Physical Systems (DPTA 2019) 2020 (pp. 1915-1923). Springer, Singapore.

[6] Muslimov R, Plotnikova I. Modeling the development of oil fields, considering the mature fields reforming and refill by the deep hydrocarbons. Neftyanoe Khozyaystvo - Oil Industry. 2019;3:56-60.

[7] Nasybullin AV, Sattarov R, Latifullin FM, Denisov OV, Chirikin AV. Creation of software tool for long-term investment planning with a view to the effective development of oil fields (Russian). Oil Industry Journal. 2019 Dec 1;2019(12):128-31.

[8] Muslimov RK, Plotnikova IN. Consideration of the processes of oil deposit reformation during long-term operation and deep feeding in modeling the development of oil fields. Георесурсы. 2018;20(3 (eng)).

[9] Buana YS, Adisatria MA, Azizurrofi AA. Paper production cost analysis of improved oil recovery projects based on field development plan in Indonesia. Society of Petroleum Engineers - SPE Kuwait Oil and Gas Show and Conference, KOGS, 2019.
[10] Altunin AE, Gordeev AO, Zemtsov YV, Zimin PV, Semukhin MV. Development of an automated matching algorithms geological and technical measures and criteria Well-ranking candidates on the basis of fuzzy sets (Russian). Oil Industry Journal. 2016 Sep 1;2016(09):949.

[11] Katasev AS, Kataseva DV. Expert diagnostic system of water pipes gusts in reservoir pressure maintenance processes. In2016 2nd International Conference on Industrial Engineering, Applications and Manufacturing (ICIEAM) 2016 May 19 (pp. 1-5). IEEE.

[12] Alekseev A, Katasev A, Kirillov A, Khassianov A, Zuev D. Prototype of Classifier for the Decision Support System of Legal Documents. CEUR Workshop Proceedings. 2020;2543:328-335.

[13] Alekseev AA, Zuev DS, Katasev AS, Tutubalina EV, Khassianov AF. Intellectual information decision support system in the field of economic justice. Nauchnyy servis V seti Internet: trudy XIX Vserossiyskoy nauchnoy konferentsii (17-22 sentyabrya 2018 g., g. Novorossiysk), Moscow, Keldysh Institute of Applied Mathematics. 2018.

[14] Baghapour MA, Shooshtarian MR, Zarghami M. Process Mining Approach of a New Water Quality Index for Long-Term Assessment under Uncertainty Using Consensus-Based Fuzzy Decision Support System. Water Resources Management. 2020 Feb;34(3):1155-72.

[15] Askari G, Gordji ME. Decision Making: Rational Choice or Hyper-Rational Choice. Statistics, Optimization \& Information Computing. 2020 May 28;8(2):583-9.

[16] Ha SH. Applying knowledge engineering techniques to customer analysis in the service industry. Advanced Engineering Informatics. 2007 Jul 1;21(3):293-301.

[17] Alonso Á, García I, Villar JR, Benavides C, Rodríguez F. Applying knowledge engineering techniques in control engineering education. IFAC Proceedings Volumes. 2003 Jun 1;36(10):279-84.

[18] Katasev AS. Neuro-fuzzy model of fuzzy rules formation for objects state evaluation in conditions of uncertainty. Computer research and modeling. 2019;11(3):477-92.

[19] Baron L, Achiche S, Balazinski M. Fuzzy decision support system knowledge base generation using a genetic algorithm. International Journal of Approximate Reasoning. 2001 Nov 1;28(2-3):125-48.

[20] Anikin IV, Makhmutova AZ, Gadelshin OE. Symmetric encryption with key distribution based on neural networks. In2016 2nd International Conference on Industrial Engineering, Applications and Manufacturing (ICIEAM) 2016 May 19 (pp. 1-4). IEEE.

[21] Emaletdinova LY, Kabirova AN. Methods of Constructing the Neural Network Models of Regulators for Controlling a Dynamic Object with Smooth Monotonous Behavior. Russian Aeronautics. 2019 Apr $1 ; 62(2): 213-21$. 
[22] Neaga EI. Semantics enhancing knowledge discovery and ontology engineering using mining techniques: A crossover review. InKnowledge Discovery and Data Mining: Challenges and Realities 2007 (pp. 163-188). IGI Global.

[23] Chupin MM, Katasev AS, Akhmetvaleev AM, Kataseva DV. Neuro-Fuzzy Model in Supply Chain Management for Objects State Assessing. Int. J Sup. Chain. Mgt Vol. 2019 Oct;8(5):201-208.

[24] Johansson J, Contero M, Company P, Elgh F. Supporting connectivism in knowledge based engineering with graph theory, filtering techniques and model quality assurance. Advanced Engineering Informatics. 2018 Oct 1;38:25263 .

Panishchev Oleg Yuryevich - Researcher of the Research Laboratory of Near Space Research of the Kazan (Volga) Federal University. In 2003, he graduated from Yelabuga State Pedagogical University with a degree in Physics, Informatics and Computer Science. Research interests: time series analysis, analysis methods of non-equilibrium distributed systems.

Ahmedshina Ekaterina Nikolaevna - Candidate of Physical and Mathematical Sciences, Senior Researcher of the Research Laboratory for Near Space Research of the Kazan (Volga) Federal University. She graduated from the Tatar State Humanitarian Pedagogical University with a degree in Physics with an additional specialty in computer science. In 2015, she defended her candidate thesis at the KFU. Research interests: logical operations on sets, logical operations with images in optical echoholography, photon echo.

Kataseva Dina Vladimirovna - graduate student, Senior Lecturer of the Department of Information Security Systems of the Institute of Computer Technologies and Information Protection of the Kazan National Research Technical University named after A.N. Tupolev-KAI (KNRTU-KAI). In 2008, she graduated from the Kazan State Financial and Economic Institute with a degree in Accounting, Analysis and Audit. In 2018, she received a master's degree at the KNRTU-KAI in the direction of Informatics and Computer Engineering. Research interests: intellectual analysis of time series, fuzzy logic, neural networks, decision-making support systems.

Anikin Igor Vyacheslavovich - Doctor of Technical Sciences, Professor, Head of the Department of Information Security Systems of the Institute of Computer Technologies and Information Security of the Kazan National Research Technical University named after A.N. Tupolev-KAI (KNRTU-KAI). In 1997, he graduated from the Yelabuga State Pedagogical Institute with a degree in Mathematics, Informatics and Computer Engineering. In 2018, he defended his doctoral thesis. Research interests: information security, intelligent systems, neural networks, fuzzy systems.

Katasev Alexey Sergeevich - Doctor of Technical Sciences, Professor of the Department of Information Security Systems of the Institute of Computer Technologies and Information Security of the Kazan National Research Technical University named after A.N. Tupolev-KAI (KNRTU-KAI). In 2002, he graduated from the Yelabuga State Pedagogical Institute with a degree in Physics, Informatics and Computer Engineering. In 2018, he received a master's degree at the KNRTU-KAI in the direction of Informatics and Computer Engineering. In 2019, he defended his doctoral thesis at the KNRTU-KAI. Research interests: data mining technologies, formation of knowledge bases of expert systems, neural network, fuzzy and neuro-fuzzy modeling.

Akhmetvaleev Amir Muratovich - Candidate of Technical Sciences, Associate Professor of the Department of Information Security Systems of the Institute of Computer Technologies and Information Security of the Kazan National Research Technical University named after A.N. Tupolev-KAI (KNRTU-KAI). In 2008, he graduated from the Kazan State University named after A.N. Tupolev with a degree in Information Security of Telecommunication Systems. In 2012, he received a master's degree at the KNRTU-KAI in the direction of "Informatics and Computer Technology". In 2018, he defended his candidate thesis at the KNRTU-KAI. Research interests: data mining, neural network modeling, assessment of human functional states by pupillary responses to changes in illumination.

Nasybullin Arslan Valerievich - Doctor of Technical Sciences, Professor, Head of the Department of Development and Operation of Oil and Gas Fields of the Almetyevsk State Oil Institute. In 1996, he graduated from the Kazan State University with a degree in Applied Mathematics. In 2012, he defended his doctoral thesis. Research interests: information technology in the development of oil fields, hydrodynamic modeling of filtration processes in porous media, hydraulic fracturing. 